\title{
Uma análise das lacunas culturais entre chinês e português na tradução do romance Viver
}

\author{
Li Huang
}

\begin{abstract}
Resumo: Muitas vez̨es, em função da falta de conhecimento do universo do texto literário da língua-fonte pelos leitores da língua-alvo, ocorre o fenómeno da 'lacuna cultural' na traducão, aqui entendida como aquela descrita por Wang (1997, p. 55): "uma falta de conbecimento do ambiente cultural relevante $e$ compartilhado entre o autor e os seus leitores pretendidos". Ademais, "a lacuna cultural é um fenómeno da comunicação de cultura-especifica, que resulta do movimento de uma cultura particular". Em se tratando de lacunas culturais, a selecção da estratégia é importante para transmitir o conceito do texto-fonte para o texto-alvo. Este artigo faz uma análise das lacunas culturais na traducão do chinês para o português do romance Viver (YU, 1993/2008), de modo a observar se as estratégias adoptadas na tradução dessas lacunas culturais transmitiram bem os significados desses termos.
\end{abstract}

Palavras-chave: lacuna cultural; tradução; chinês; português; Viver

\section{Lacuna cultural}

Dagut (1978, p. 45) define o termo lacuna como "a não-existência de uma equivalência de um termo duma língua em outra"3 (minha tradução).

Ele identifica quatro tipos de lacunas e propõe estratégias para supri-las:

a) Ambiental;

b) Cultural;

1 Tradução minha para: [Absence of relevant cultural background knowledge shared by the author and his/her intended reader.]

2 Tradução minha para: [Cultural default is a culture-specific communication phenomenon and it is a result of the movement of a particular culture.]

3 [Non-existence in one language of a one-word equivalent for a designatory term found in another.] 
c) Lexical: embora não tenha um termo equivalente, a conotação que o termo-fonte carrega pode existir na experiência dos leitores da língua-alvo. Para este tipo de lacuna, três técnicas de tradução são sugeridas: 1) selecciona-se um termo na língua-alvo que carrega uma parte da conotação do termo na língua-fonte; 2) faz-se a paráfrase de algumas características do termo na língua-fonte; 3) faz-se a omissão.

d) Sintática: "é causada pelas assimetrias estruturais entre uma dada língua-fonte e uma dada língua-alvo"4 (minha tradução). O autor sugere o ajuste sintáctico para que o leitor da língua de chegada entenda o texto. (DAGUT, 1978, p. 89).

Conforme Wang (1997, p. 55), a lacuna cultural é "uma falta de conhecimento do ambiente cultural relevante e compartilhado entre o autor e os seus leitores pretendidos" (minha tradução). Também aponta que "a lacuna cultural é um fenómeno da comunicação de cultura-específica, que resulta do movimento de uma cultura particular" (ibidem) (minha tradução).

A lacuna na tradução ocorre, conforme Gutt (1991/2000), "devido à diferença do ambiente cognitivo; pois, aos leitores da língua-alvo falta o conceito ou informação suficiente associado à concepção da língua-fonte" (minha tradução). Gutt também considera que a lacuna é inevitável na tradução (ibidem, p. 120), e para que determinado conceito do texto-fonte seja transmitido adequadamente aos leitores-alvo, é importante fazer uma selecção das estratégias de tradução. Dagut (1978) propõe algumas estratégias para compensar essas lacunas. Algumas delas podem ser empregadas na prática da tradução, como veremos a seguir, mais detalhadamente.

\section{Análise das lacunas culturais na tradução de Viver}

Yu Hua, autor do romance Viver, nasceu em 1960 em Hangzhou, capital da província de Zhejiang. Foi o primeiro escritor chinês a receber o Prêmio da Fundação James Joyce, em 2002. Viver, considerado um dos romances chineses

\footnotetext{
4 [These are caused by 'structural asymmetries between SL and TL'.]

5 [Absence of relevant cultural background knowledge shared by the author and his/her intended reader.]

6 [Cultural default is a culture-specific communication phenomenon and it is a result of the movement of a particular culture.]

7 [Due to differences in cognitive environment, the receptor language audience lacks information associated with a concept in the original.]
} 
mais influentes da década de 1990, ganhou o prémio italiano Grinzane Cavour em 1998 e foi publicado em mais de treze países. Em 1994, o cineastra chinês Zhang Yimou adaptou-o para o cinema com o nome de Tempos de Viver, que foi aclamado pela crítica e pelo público.

O romance passa-se no início dos anos quarenta, quando a família $X u$, que residia numa aldeia do interior da China, gozava duma vida confortável e próspera. Os seus antepassados acumularam riqueza o suficiente para o conforto da família, podendo sustentar as gerações posteriores. Ao fim da Segunda Guerra Mundial e da ocupação japonesa, quando as tropas nacionalistas tratavam da recuperação das terras usurpadas pelo invasor, Fugui, filho único da família $\mathrm{X}$, perdeu tudo por causa do seu gosto pelo jogo e pelas mulheres, deixando a família numa enorme dívida. A vida caiu numa pobreza absoluta. Para sustentar a família, Fugui conseguiu obter uma parcela de terra e começou uma vida nova. Viver é um romance que conta a trajectória da China contemporânea através da descrição épica da família $X u$.

Márcia Schmaltz, tradutora deste romance, é natural do Brasil tendo trabalhado como tradutora e intérprete em português e em chinês na área comercial. É actualmente professora de língua portuguesa e tradução na Universidade de Macau. Ainda criança, morou por seis anos em Taiwan, em consequência do casamento da mãe com um chinês. A obra foi traduzida directamente do chinês para o português tendo sido publicada no Brasil em 2008. A experiência como tradutora e intérprete, a vivência em Pequim e o contacto constante com a China oferecem-lhe uma ampla visão que lhe ajuda muito na sua carreira da tradução.

\subsection{Técnicas tomadas na tradução das lacunas culturais em Viver}

A técnica de domesticação tem como foco tornar a leitura fluente aos leitores da língua-alvo, objectivando levar o autor aos leitores-alvo, enquanto que a técnica de estrangeirização é uma tentativa de fazer com que os leitores-alvo se aproximem do texto-fonte, ou seja, ela conduz os leitores da língua-alvo até o autor da obra original. Veremos que no romance Viver (YU, 2008), a tradutora empregou tanto a domesticação como a estrangeirização ao se deparar com diferentes tipos de lacunas culturais.

\subsubsection{Domesticação}

A domesticação pretende aproximar o autor dos leitores da língua-alvo. Venuti (2004) afirma que esta técnica tem que ser fluente e clara, de modo a diminuir 
o estranhamento que o texto-fonte eventualmente pode causar nos leitores-alvo. A domesticação ainda pode empregar outras medidas tais como tradução por sentido, substituição e paráfrase, abordadas a seguir.

\subsubsection{TRADUÇÃo POR SENTIDO}

A tradução por sentido é literalmente traduzir o sentido de termos do texto-fonte (TF) para facilitar a compreensão dos leitores.

Exemplo 1:

TF: 我却怎么都睡不着，心里七上入下的，家珍那样子像是好多了，可 我老怕这是不是人常说的回光返照。(YU, 1993, p. 54)

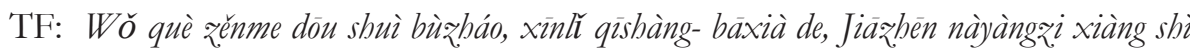
hăoduōle, kè wŏ lăo pà zhè shì bùshì rén cháng shuō de buiguäng-fănz̧̧ào (YU, 1993, p. 54)

TA: Eu, por minha vez, estava assustado e não conseguia dormir. Jiazhen parecia bem melhor, mas eu temia que fosse apenas uma recuperação aparente, $\underline{0 \text { último }}$ brilho do sol antes do poente. (YU, 2008, p. 149)

“回光返照 huiguäng-fănzḩào” refere-se a um fenómeno natural, que remete a imagem do brilho temporário do céu, devido ao reflexo dos raios solares nas nuvens, antes de cair rapidamente a escuridão. Esta expressão é metafórica, descrevendo o estado de ânimo que uma pessoa pode ter antes de morrer.

Jiazhen estava doente, e não tinha forças para ficar de pé. De acordo com o diagnóstico do médico, ela iria morrer em breve. Contudo, um dia melhorou e conseguiu se levantar da cama e até fazer alguns trabalhos domésticos. Fugui ficou surpreso com a sua melhora repentina e o súbito falecimento, por isso utilizou aquela expressão.

Dagut (1978) propõe três técnicas de tradução da lacuna cultural desse tipo: 1) selecciona-se um termo na língua-alvo que carrega uma parte da conotação do termo na língua-fonte; 2 ) faz-se a paráfrase de algumas características mais salientes do termo da língua-fonte para o termo da língua-alvo; 3) Omite-se.

Para transmitir o significado adequado desta expressão “回光返照 buiguāng-fănz̧hào", a tradutora fez uma interpretação apropriada e conhecida pelos leitores brasileiros, "o último brilho do sol antes do poente", por meio da qual os leitores-alvo inferem a conotação de sentido mais naturalmente, conforme o contexto em que se enquadra a expressão. 


\subsubsection{Substituiç̧̃̃o}

A substituição, segundo Beekman e John (1974, p. 201), refere-se à utilização de termo existente na cultura-alvo para descrever o termo no texto-fonte, quando ambos os termos têm a mesma função.

Exemplo 2:

TF: 我丈人当时的脸就和松花蛋一样, 我呢, 嘻嘻笑着过去了。(YU, 1993, p. 11)

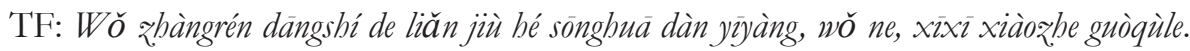
(YU, 1993, p. 11)

TA: O rosto de meu sogro ficava vermelho como um pimentão. Eu me afastava rindo. (YU, 2008, p. 16)

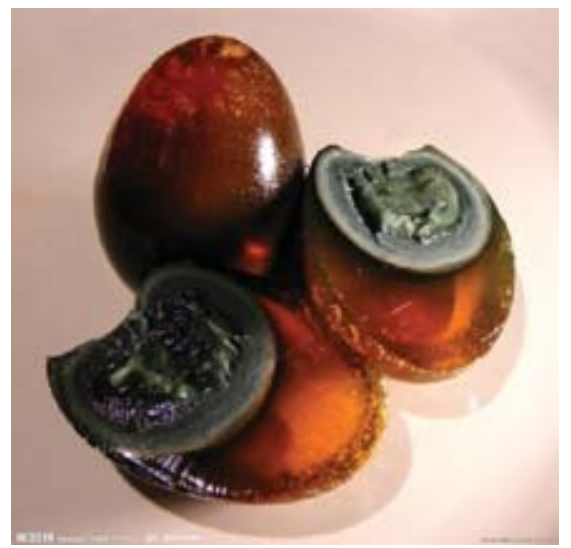

(Figura 1: Imagem de “松花蛋 sōnghuā dàn”. Fonte: http://health.lznews.cn/2011/0717/426 469.html. Acesso em: 26 de abril de 2013)

Na base da classificação de cultura proposta por Newmark (2001), o termo “ 松花蛋 sōnghuā dàn” pertence à cultura material do domínio da alimentação. Para que a tradução de “松花蛋 sōnghuá dàn” seja aceitável na língua-alvo, a tradutora recorreu à substituição. Nesta frase, “松花蛋 sōnghuā dàn” foi traduzido por “pimentão”.

Segundo Huang (2008), para traduzirmos este tipo de lacuna cultural, podemos empregar a técnica de transliteração com uma nota de rodapé para apresentar mais conhecimento sobre o termo da cultura fonte, no caso, “松花蛋 sōnghuā dàn". Neste caso, a tradutora preferiu uma substituição. 
Conforme a narrativa, Fugui é viciado em jogo e tinha recaída por mulheres. Mesmo ele estando casado com a Jiazhen, sempre ia para o prostíbulo. E sempre que levava outra mulher à loja do seu sogro, cumprimentava-o, fazendo com que este ficasse zangado e envergonhado.

Neste caso, o texto-fonte utilizou o recurso de símile para descrever a expressão do rosto do sogro do Fugui. A cor interna de “松花蛋 sōnghua dàn” é verde escura. $\mathrm{Na}$ cultura chinesa, às vezes emprega-se este termo para denotar a expressão facial duma pessoa zangada, e em alguns casos, usa-se também diretamente a cor verde para expressar esta situação, como “铁青的脸 tièquing de liăn" (literalmente rosto verde como o ferro) $)^{8}$. O termo chinês indica a cor do rosto do sogro de Fugui depois deste receber outra mulher na loja. Segundo o Dicionário Contemporâneo da Lingua Portuguesa Caldas Aulete, "pimentão" pode ser dito "de alguém que está com o rosto vermelho (por queimadura de sol, p. ex.) ou muito corado, ruborizado (de excitação, vergonha etc.)". A expressão "vermelho como pimentão" descreve o rosto do sogro de Fugui, que "estava zangado e envergonhado com as atitudes do genro", e é uma expressão da cultura brasileira.

Os dois termos manifestam aspecto figurativo semelhante, pois ambos descrevem a situação zangada do sogro de Fugui. Configura-se, assim, o uso de simile, relacionado com o contexto.

Exemplo 3:

TF: 被包围的不只是我们一个连, 有十来万人的国军全被包围在方圆只有 二十来里路的地方里, 满地都是黄衣服, 像是赶庙会一样。(YU, 1993, p. 54)

TF: Bèi bāowéi de bù zhĭshì wǒmen yigè lián, yǒu shí lái wàn rén de guójün quán bèi bāowéi

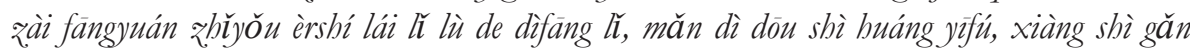
miàobui yiyàng. (YU, 1993, p. 54)

TA: Além da nossa companhia, mais de cem mil soldados nacionalistas foram cercados num raio de apenas vinte lis. Todos ali estavam usando uniformes da mesma cor, como se fossem participar de uma quermesse. (YU, 2008, p. 61)

Conforme o Grande Dicionário da Língua Chinesa [辞海 cíbăi], “庙会 miàobui" é uma feira de mercadorias realizada nas cercanias de um templo, que existe desde a dinastia Tang (618-907) ${ }^{9}$.

8 Disponível em: <zhidao.baidu.com/question/180397336.html?fr=qrl\&cid=978\&index=1\&fr2= query.> Acesso em 7 de julho de 2011.

9 [Grande Dicionário da Lingua Chinesa] (1999, p. 1030). 
O termo "quermesse", conforme o dicionário Infopédia, é "1) festival com leilão e venda de prendas, com fim beneficente; 2) venda de artigos geralmente artesanais para fins de beneficência; bazar; 3) designação das festas paroquiais, com feira anual, procissões e outras manifestações populares; 4) festa animada e barulhenta."

Os dois termos têm tanto semelhanças como diferenças. Ambos os termos descrevem as feiras de venda, porém, “庙会 miàohui” na China é sempre realizada perto do templo. Nos tempos antigos, “庙会 miàobui” também se constituía como uma cerimónia para prestar homenagem às divindades. A par do desenvolvimento económico e da crescente necessidade do intercâmbio entre as pessoas, esta actividade começou a se tornar uma feira com fins de venda de prendas e de diversão.

A tradutora substituiu o termo “庙会 miàobui” por “quermesse”, que é uma expressão da atividade religiosa cristã, conhecida pelos brasileiros, que também carrega uma conotação cultural brasileira. Embora existam diferenças entre o termo original e o traduzido, neste caso, os leitores-alvo podem compreender facilmente o sentido sem muito esforço.

\subsubsection{PARÁfrase}

Dryden (1989, p. 8) define a paráfrase como "a tradução com latitude, onde o tradutor procura manter o autor ao alcance dos olhos para nunca perdê-lo de vista; contudo a tradução não segue tão estritamente as palavras do original, pois se atem mais ao sentido"10 (minha tradução). Ele privilegia a paráfrase na tradução e argumenta que este método de tradução pode "transferir o espírito do autor" (minha tradução) (ibidem, p. 11).

Exemplo 4:

TF: 年过花甲的私塾先生对我爹说：“你家少爷长大了准能当个二流 子。”(YU, 1993, p. 8)

TF: Niánguò buäjiă de sìshú xiänshèng duì wǒ diè shuō: "Nǐ jiā shàoyé zhăng dàle zhŭn néng dāng gè èrliuizi." (YU, 1993, p. 8)

TA: Meu professor particular era um homem de bastante idade. Ele dizia para o meu pai: Esse seu filho, quando crescer, vai ser a escória da sociedade. (YU, 2008, p. 13)

10 [Translation with latitude, where the author is kept in view by the translator, so as never to be lost, but his words are not so strictly followed as his sense.]

11 [The spirit of an autor may be transferred.] 
Conforme o livro Profissões Tradicionais Chinesas (2008, p. 41), o termo “私塾 sish $u$ ” designa profissionais do ensino: “alguns deles eram professores experientes, outros letrados que não passavam nos exames distritais ou, oriundos de outras cidades. Muitos, não satisfeitos com as receitas que obtinham, criaram escolas próprias e foi assim que nasceu “私塾 sīshî̉." A concepção de “私塾 sīshû̉ é típica da dinastia Qing (1644-1911). A família Xu é muito rica, por isso contratava “私塾先生 sishú xiänshèng” ou “塾师 shuishì" para ensinar o seu filho Fugui em casa.

“私塾先生 sīshú xiānshèng” é uma profissão chinesa que pertence à cultura social. De acordo com as três técnicas para a tradução desse aspecto cultural proposta por Dagut (1978, p. 89), pode ser constatado que a tradutora empregou a paráfrase.

Ao invés de fazer uma tradução estrangeirizante, a tradutora fez uma paráfrase, e traduziu por "meu professor particular", tornando a compreensão mais fácil na língua-alvo. Através da tradução, confome o contexto e as inferências, os leitores-alvo podem perceber o significado do texto traduzido.

Exemplo 5:

TF: 现在想想他们都说对了, 当初我可不这么想, 我想我有钱呵, 我是 徐家仅有的一根香火, 我要是灭了, 徐家就得断子绝孙。(YU, 1993, p. 8) TF: Xiànzài xiăng xiăng tämen dōu shuō duile, dāngchū wǒ kèbù zhème xiăng, wǒ xiăng

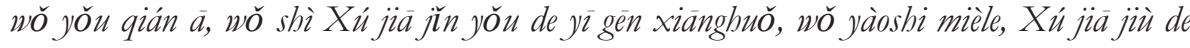
duàn ₹̌juésün. (YU, 1993, p. 8)

TA: Pensando bem, eles estavam certos. No início, eu não aceitava. Eu pensava: tenho dinheiro, sou filho único, se eu bater as botas, lá se vai a família Xu. (YU, 2008, p. 13)

Com base nas categorias de classificação culturais de Newmark (2001), “香 火 xiānghuŏ” é uma entidade pertencente à cultura social. Dentre as três técnicas propostas por Dagut (1978) comentado acima, a tradutora empregou a segunda técnica, que é a paráfrase.

“香火 xiänghuŏ” refere-se ao lume dos incensos. Conforme o romance, o Fugui é “仅有的一根香火 jünyǒu de yì gèn xiānghuö” da família Xu, isso significa que ele é o filho único da família Xu, que pertence ao âmbito dos costumes e regramentos sociais (NEWMARK, 2001) da China. Se o incenso for apagado (灭 miè), a continuidade da linhagem familiar será interrompida. Neste caso, a tradutora fez uma paráfrase e traduziu por "sou filho único", seguida pela respectiva frase explicativa: "se eu bater as botas, lá se vai a família Xu". 
No Dicionário Informal, a origem da expressão "bater as botas" remonta "à primeira invasão holandesa, ocorrida em Salvador, em 1624, os negros comportaram-se bravamente diante do invasor. Não estavam acostumados com os armamentos que lhes foram dados, e constantemente tropeçavam nas próprias botas, virando um alvo fácil para os holandeses. Então os outros negros costumavam dizer que a pessoa havia batido as botas. Daí nasceu esta expressão, que significa morrer". ${ }^{12}$ A tradução ostensiva manifesta o papel importante do Fugui na família $X u$. Através da adaptação da expressão do TF na tradução, pretende-se oferecer os mesmos efeitos do TF aos leitores da língua-alvo:

a) Fugui é o filho único da família Xu.

b) Se ele bater as botas, interrompe-se a continuação da linhagem da família Xu.

c) Fugui exerce um papel muito importante na família Xu, conforme a) e b).

Os leitores da língua-alvo podem perceber a tradução, porém, talvez não saibam sobre esta nuance cultural chinesa, em que apenas um filho do sexo masculino é capaz de exercer a função de continuidade da linhagem da família. $\mathrm{Na}$ tradução desta lacuna cultural, às vezes, não se pode transmitir perfeitamente o significado dos termos do texto-fonte devido a esta diferença cultural profunda. Isso não depende da capacidade da tradutora.

\subsubsection{EstrangeIRIZAÇÃo}

A técnica de estrangeirização faz com que os leitores da língua-alvo aproximem-se do autor do texto original. Venuti (2004) explica que a estratégia de estrangeirização conserva os elementos exóticos do texto-fonte quando o tradutor faz a tradução. $\mathrm{Na}$ tradução deste romance, há dois tipos de estrangeirização: a transliteração sem nota de rodapé e a com uma nota de rodapé.

\subsubsection{TRANSLITERAÇÃo SEM NOTA DE RODAPÉ}

Conforme Huang (2008, p. 29), "há cada vez mais lacunas culturais que podem ser transmitidas com suficiente intercâmbio cultural”"13 (minha tradução),

12 Disponível em: http://www.dicionarioinformal.com.br/definicao.php?palavra=bater+as+botas. Acesso em: 5 de julho de 2011.

13 [More and more cultural defaults would become transplantable with sufficient cultural exchange.] 
por isso, "algumas lacunas culturais podem ser traduzidas literalmente na língua-alvo sem nenhuma explicação"14 (minha tradução). Veja o exemplo abaixo:

Exemplo 6:

TF: 家珍那时候可真漂亮, 头发齐齐地挂到耳根, 走去时旗袍在腰上一皱 一皱, 我当时就在心里想, 我要她做我的女人。(YU, 1993, p. 19)

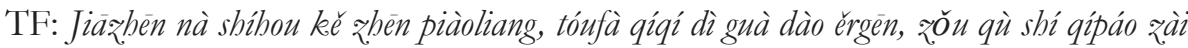

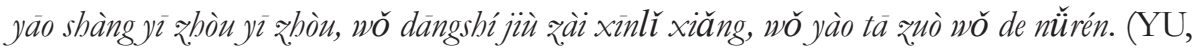
1993, p. 19)

TA: A Jiazhen daqueles tempos era muito bonita: o cabelo penteado rente atrás da orelha, com as pregas do qipao dançando na cintura enquanto ela caminhava. Naquele momento, pensei: quero que ela seja minha mulher. (YU, 2008, p. 25)

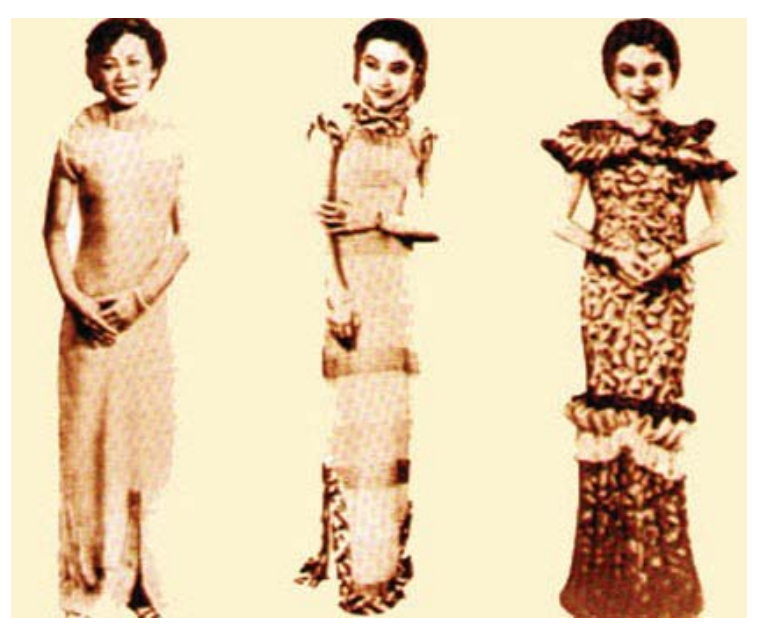

(Figura 2: Imagem de “旗袍 qípáo”. Fonte: http://gb.cri.cn/3601/2005/03/17/882 @484090.htm. Acesso em: 26 de abril de 2013)

O grande dicionário da língua chinesa [辞海 cíbăi] (1999, p. 2328) indica que “旗袍 qípáa” é um vestuário feminino típico da China, que remonta ao vestuário tradicional da etnia Manchu, a figura de “旗袍 qípáo" é mostrada na Figura 4. A tradutora fez uma transliteração, introduzindo esta concepção aos leitores da língua-alvo. Neste caso, a tradução fez uma ostensão de que o termo na língua-fonte não existe na cultura da língua-alvo. Os leitores-alvo têm de fazer inferências através desta tradução:

14 [Some cultural default can be translated literally into target language text without any explanation.] 
a) “旗袍 qípáo" é um vestuário que modela o corpo, conforme as palavras "prega", "cintura".

b) “旗袍 qípáo" é um vestuário feminino, conforme a frase "dançando na cintura enquanto ela caminhava" (YU, 2008, p. 25).

Dagut (1978) e Huang (2008) propõem a estratégia de transliteração acompanhada com uma nota de rodapé para as traduções relativas à cultura.

Mas, neste caso, a tradução literal “旗袍 qípáo” não é suficiente para os leitores da língua-alvo capturarem a imagem referenciada pelo item lexical. Embora a tradução tente transmitir o significado do termo, esta tradução não ofereceu mais elementos visando a uma melhor compreensão do leitor, por faltar informações contextuais suficientes para a inferência. Se adicionarmos uma nota de rodapé, mais efeitos poderão ser inferidos pelos leitores-alvo.

\subsubsection{TRANSLiteraçÃo COM NOTA DE RODAPÉ}

Huang (2008, p. 30) diz que "alguns textos com lacunas culturais são muito específicos e é quase impossível que sejam aceitos directamente pelos leitores da língua-alvo; neste caso, a estratégia de transliteração com notas pode ser uma maneira efetiva de lidar com a questão"15 (minha tradução). Na tradução deste romance, a tradutora empregou a transliteração com nota de rodapé em alguns casos.

Exemplo 7:

TF: 家珍怀着有庆有六个月了, 自然有些难看, 走路时裤禅里像是夹了 个馒头似的一粕一粠, 两只腿不往前往横里跨。(YU, 1993, p. 9)

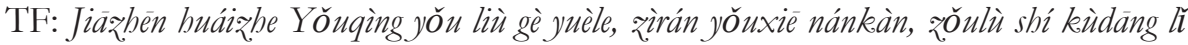

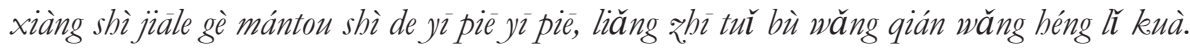
(YU, 1993, p. 9)

TA: Jiazhen estava um tanto deformado em razão da gravidez de seis meses de Youqing; ela caminhava como se tivesse um mantou $^{\text {ep }}$ no meio das pernas, que a fazia andar que nem uma pata com as pernas abertas. (YU, 2008, p. 15)

apPão chinês feito à base de farinha de trigo, fermento e água e assado no vapor. (N.T.)

15 [Many texts with cultural defaults are so culture-specific that it is almost impossible for them to be accepted directly by the target reader. In this case, literal translation with notes should be an effective way to deal with the problem.] 


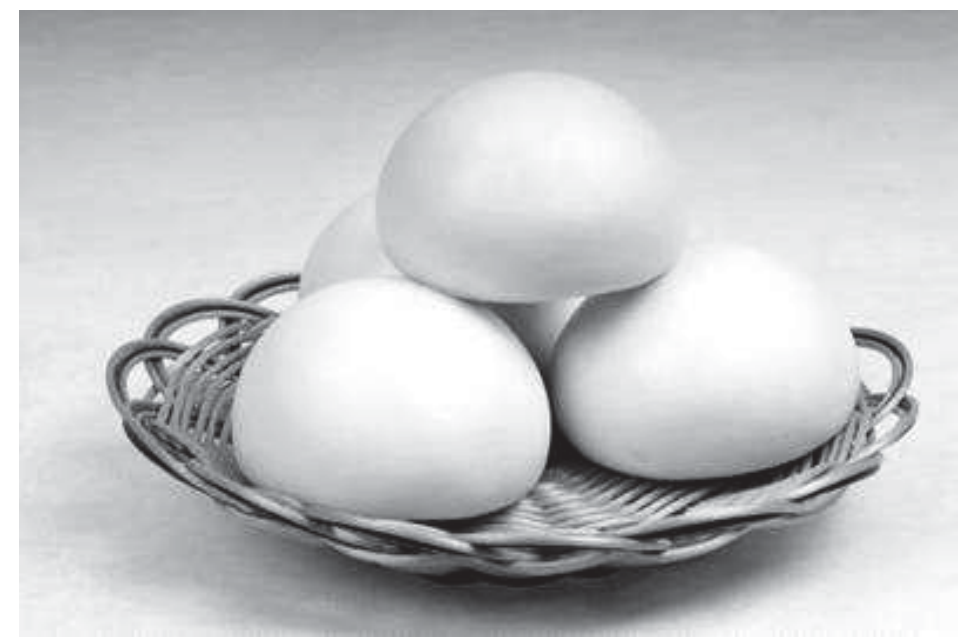

(Figura 3: Imagem de “馒头 mántóu”. Li Huang. Disponível em: http://whty.whjs.gov.cn/images/ 2008-01/03/xinsrc_4401050310158282978920.jpg. Acesso em: 26 de abril de 2013)

“馒头 mántóu”, um dos alimentos mais populares na China, é um tipo de pão cozido à vapor. Os leitores da língua-alvo que não têm o conhecimento sobre o “馒头 mántóu”, espécie de pão, vão deparar-se com uma lacuna cultural aqui. Por isso, a estratégia de anotação através duma nota de rodapé ficou bem neste contexto, para uma melhor compreensão. Através da anotação, os leitores-alvo também podem conhecer mais sobre a cultura chinesa.

Para este tipo de lacuna, Dagut (1978) sugere a estratégia de transliteração acompanhada de nota de rodapé para dar mais informações aos leitores da língua-alvo. A tradutora empregou esta técnica neste exemplo. Nesse romance, além de “馒头 mántóu”, outros termos da alimentação típica chinesa foram citados e traduzidos através da transliteração com nota de rodapé, como “亘腐dòufu, 大饼 dà bǐng, 包子 bāozi e 白酒 báijiǔ”, “包子 bāozi” e “白酒 báijiǔ”. “亘腐 dòufu” é conhecido como "tofu”, o queijo de soja, correspondente à cultura dos leitores-alvo. “大饼dà bǐng” ou simplesmente 饼 bǐng, um tipo de massa em forma de disco, feita de farinha, água e ovos e assada na chapa. “包子 bāozi” é uma espécie de salgadinho chinês, recheado com carne e/ou verduras. “白酒 báijiư” é um tipo de aguardente chinês, destilado principalmente do sorgo, ao qual podem ser adicionados outros grãos. Com estas anotações, os leitores da língua-alvo podem captar melhor o sentido do texto-fonte. 


\section{Considerações finais}

Este trabalho teve como objectivo observar quais foram as estratégias adoptadas na tradução à língua portuguesa do romance Viver de Yu Hua (2008) diante de algumas lacunas culturais.

Através da análise das traduções das lacunas culturais do romance Viver, chegamos à seguinte conclusão: $\mathrm{O}$ sucesso da tradução de lacunas culturais não é apenas restringido pela capacidade do tradutor, mas também pelas diferenças linguística e cultural, especialmente a distância geográfica entre os dois países. Cada técnica tem a sua vantagem e desvantagem. Em alguns casos, a tradução não foi ostensiva o suficiente. A técnica de domesticação pode facilitar a compreensão dos leitores da língua-alvo, porém, perde às vezes a imagem figurativa presente no termo do texto-fonte. A transliteração sem nota de rodapé pode apresentar novo conhecimento da cultura do texto-fonte, contudo, não oferece informações suficientes quanto a este termo, enquanto que a transliteração com nota de rodapé, embora ofereça as informações necessárias, irá influenciar o fluxo da leitura dos leitores.

\section{Referências}

AULETE, F. J. C. V., SANTOS, A. L. Dicionário contemporâneo da língua portuguesa Caldas Aulete. Edição brasileira original: Hamílcar de Garcia, 2009.

BEEKMAN, J. e JOHN, C. Translating the Word of God, Grand Rapids, Michigan: Zondervan, 1974.

Cihai (辞海) [Grande Dicionário da Lingua Chinesa]. Xangai: Editora de CISHU de Xangai, 2000.

DAGUT, M. Hebrew-English Translation: A Linguistic Analysis of Some Semantic Problems. Haifa: University of Haifa, 1978.

DRYDEN, J. "Metaphrase, Paraphrase and Imitation”. In: Andrew Chesterman (Ed.), Reading in Translation Theory, Helsinki: Finn Lectura, 1989, pp. 7-12.

GUTT, E. A. Translation and Relevance: Cognition and Context. Xangai: Xangai Foreign Language Education Press, 2000.

HUANG. H. (黄华) 《从关联理论看文化缺省的翻译》[“a Tradução das Lacunas culturais à luz da Teoria da Relevância”]. Dissertação de Mestrado não publicada. Guizhou: Universidade Normal de Guangxi, 2008.

NEWMARK, P. A Textbook of Translation. Xangai: Xangai Foreign Language Education Press, 2001. 
VENUTI, L. The translator's invisibility. Xangai: Editora da Educação da Língua Estrangeira de Xangai, 2004.

WANG, D. F. (王东风) “文化缺省与翻译中的连贯重构” [Lacuna cultural e a Reconstrução da Coerência na Tradução], In:《外国语》[Lingua Estrangeira], 1997, Vol. 6, pp. 55-60.

YU, H. (余华) 《活着》[Viver]. Xangai: Editora da Literatura e da Arte, 1993.

YU, H. Viver, tradução de Márcia Schmaltz. São Paulo: Companhia das Letras, 2008. 